\title{
Squamous Odontogenic Tumour - A Paradoxical Pathology
}

\author{
Sam John Koshy ${ }^{1}$, Dr Senthilnathan ${ }^{2}$ and Madhulaxmi M ${ }^{3}$ \\ ${ }^{1}$ Department of Oral \& Maxillofacial Surgery Saveetha Dental College and Hospitals, Saveetha \\ Institute of Medical And Technical Science, Saveetha University, Chennai- 600077, India \\ ${ }^{2}$ Department of Oral \&t Maxillofacial Surgery Saveetha Dental College and Hospitals, Saveetha \\ Institute of Medical And Technical Science, Saveetha University, Chennai- 600077, India \\ ${ }^{3}$ Professor and Head of Department, of Oral \& Maxillofacial Surgery Saveetha Dental College and Hospitals, \\ Saveetha Institute of Medical And Technical Science, Saveetha University, Chennai- 600077, India
}

\section{ABSTRACT}

Squamous odontogenic tumors (SOTs) are neoplasms being benign, local in origin and infiltrative in capacity that localize to the periodontium. In total, only less than 50 cases have been reported since the first description of SOTs in 1975. The most common site of occurrence of the lesion in the maxilla, incisor area and in the mandible, the bicuspidmolar region. Squamous odontogenic tumors show a characteristic triangular-shaped, unilocular radiolucency of the alveolar bone, with the wide base of the radiolucency localized between the diverging apices of the adjacent roots, radiographically. Here, we report an unusual presentation of the tumour in the periapical region of the mandibular incisor region mimicking radicular cyst clinically but with a major histological variation.

\section{KEY WORDS: SQUAMOUS ODONTOGENIC TUMOR, ORAL AND MAXILLOFACIAL TUMOR, ODONTOGENIC TUMORS.}

\section{INTRODUCTION}

Paradoxical refers to something that seems selfcontradictory. It often depicts an identity so impossible or difficult to understand because of two opposite facts or characteristics it contains. (PARADOXICAL | meaning in the Cambridge English Dictionary, no date) This case report is in fact of a paradoxical pathology because of how clinically contradictory it was when compared to all the literature present to refer to. Its contradiction has made this stand a notch different from all other cases judging by its clinical significance and presentation.

\section{ARTICLE INFORMATION}

*Corresponding Author: madhulaxmi@saveetha.com Received 27th July 2020 Accepted after revision 24th Sep 2020 Print ISSN: 0974-6455 Online ISSN: 2321-4007 CODEN: BBRCBA

Thomson Reuters ISI Web of Science Clarivate Analytics USA and Crossref Indexed Journal

\section{Clarivate
Analytics}

NAAS Journal Score 2020 (4.31) SJIF: 2020 (7.728)

A Society of Science and Nature Publication,

Bhopal India 2020. All rights reserved.

Online Contents Available at: http//www.bbrc.in/

Doi: http://dx.doi.org/10.21786/bbrc/13.8/128
World Health Organization (WHO) tumor classification published in 1971(Philipsen and Reichart, 2006) has shed an understanding on the presence of a lesion called Squamous Odontogenic Tumor. A novel and completely revised WHO classification from 2005, encompassed the histopathological and genetic criteria of SOTs, described this pathology as a group of epithelial odontogenic tumors comprising within the ameloblastoma family, consisting of solid/multicystic, extraosseous/peripheral, desmoplastic and unicystic ameloblastoma, and squamous, adenomatoid, calcifying and keratocystic odontogenic tumors(World Health Organization and International Agency for Research on Cancer, 2005).

Squamous odontogenic tumors (SOTs) are rare benign tumors of the periodontium that possess an unknown etiology and were first described in 1975 by Pullon et al (Pullon et al., 1975; Perdigão et al., 2004). In the literature, a little over fifty cases have been reported worldwide (Reichart and Philipsen, 1990; Saxby, Rippin and Sheron, 
1993). Squamous odontogenic tumors are slow-growing, locally infiltrating tumors with only a few clinical signs and symptoms which vary from patient to patient. Mobility of the teeth, increased periodontal pocket depth, sensitivity, swelling of the alveolar process, swelling and erythema of adjacent gingiva and moderate pain are the most widely accepted indicators for the underlying tumor. (Reichart and Philipsen, 1990; Saxby, Rippin and Sheron, 1993; Philipsen and Reichart, 1996). SOTs have also been reported to occur in various age groups, yet mainly affect adults in the third decade of life (Kim, Mintz and Stevens, 2007). Literature has shown that the male to female gender predilection is 1.4:1 (Reichart and Philipsen, 1990; Ruhin et al., 2007). The jaw most commonly affected is the mandible more often than the maxilla, with an increased preference of occurrence in the posterior premolar and molar area. Maxillary SOTs are described to be primarily present in the anterior area, and appear to be more aggressive in nature when compared with SOTs in the mandibular area(Reichart and Philipsen, 1990)(Reichart and Philipsen, 1990; Ruhin et al., 2007)(Reichart and Philipsen, 1990).

Squamous odontogenic tumors derive from the epithelial cell rests of Malassez where tumor appear on the lateral root surface. The typical radiographic presentation is a triangular radiolucent defect involving the lateral root surface of erupted and vital teeth(Cillo, Ellis and Kessler, 2005). The wide base of the radiolucency is localized between the diverging apices of the adjacent roots (Haghighat, Kalmar and Mariotti, 2002). The prognosis of squamous odontogenic tumor therapy is good if surgical enucleation of the whole lesion is done with curettage of the affected area with extraction of the affected teeth, if present. Recurrence appears to be rare, and may occur due to incomplete tumor removal.

With a rich case bank established over 3 decades we have been able to publish extensively in our domain (Abdul Wahab et al., 2017; Eapen, Baig and Avinash, 2017; Patil et al., 2017; Jain and Nazar, 2018; J et al., 2018; Marimuthu et al., 2018; Wahab et al., 2018; Abhinav et al., 2019; Ramadorai, Ravi and Narayanan, 2019; Senthil Kumar et al., 2019; Sweta, Abhinav and Ramesh, 2019). Here, we report an unusual presentation of the tumour in the periapical region of the mandibular incisor region mimicking radicular cyst clinically but with a major histological variation.

Case Report: A 26 year old male patient reported to the Department of oral and maxillofacial surgery complaining of pain and swelling on the right side of his face for a duration of 3 years. Pain was intermittent and slowly increased in intensity over 3 years as the patient was negligent to the initial signs and symptoms. Swelling subsequently increased with accompanying pain and discomfort while mastication and speech. Patient had a history of bruxism. There were no other relevant medical, surgical, family or personal history. On clinical examination, a definitive swelling of the face on the right side was evident with a size of $3 \mathrm{X} 3$ centimeters extending from the right corner of the mouth,
3 centimeters medial to the angle along the lower border of the mandible. Skin discolorations were evident on the right side The skin over the swelling appeared shiny with a firm consistency, with absence of tenderness on the affected area. The borders were well defined with absence of warmth over the swelling, ulcerations and pulsations.

On intraoral examination, the lower anterior teeth of the left side (31) showed discolorations suggestive of non vitality. The remaining anterior teeth were tender on vertical percussion. A swelling of the right side vestibule extending from the region of the right mandibular canine to the left lateral incisors were observed with absence of pain on palpation of the vestibule. [Figure 1] On radiographic analysis, orthopantomography of the patient revealed well defined, circumscribed, definitive bordered periapical radiolucency, diffused triangular in shape extending from the peri apical region of the right mandibular canines to the left mandibular canine measuring approximately around 3 X 5 millimeter in size periapically of each tooth. [Figure 2]

Figure 1: Intra oral image of the left, center and right side of the patient while in occlusion revealing discoloration of the lower anterior teeth of the left side (31) and swelling of the right side vestibule extending from the region of the right mandibular canine to the left lateral incisors.

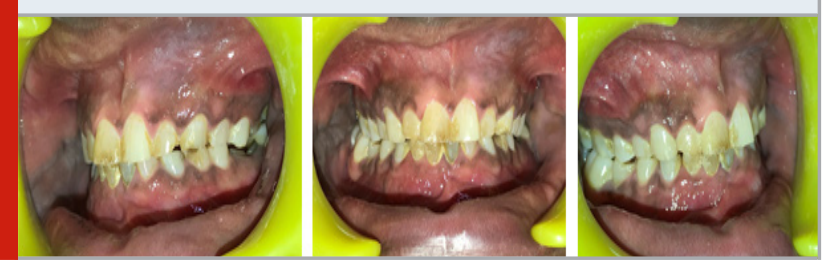

Figure 2: Pre-operative orthopantamography revealing well defined, circumscribed, definitive bordered periapical radiolucency, diffused triangular in shape extending from the peri apical region of the right mandibular canines to the left mandibular canine measuring approximately around 3 X 5 millimeter in size periapically of each tooth

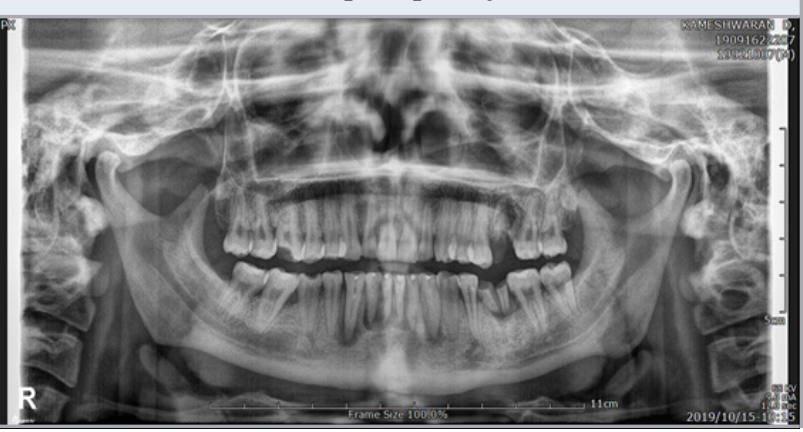

Patient history, clinical examination and radiological investigation suggested a provisional differential diagnosis of a benign pathology - radicular cyst in relation to the non vital teeth or a benign tumour. As patient was reluctant for local anaethesia procedure, treatment plan was made for an excisional biopsy under General anesthesia. Surgical procedure followed 
a crevicular incision followed by releasing incisions extending from the region of the right mandibular canine to the left mandibular canine and the lesion was exposed. Enucleation of the lesion and post- enucleation prophylactic saucerization of the bone adjacent to the lesion was done. Simultaneous apicectomy with retrograde mineral trioxide aggregate filling and osseous reconstruction using Concentrated Growth Factors and xenograft Bone grafts (Geistlich Bio-0ss) was done as the lesion resembled a cyst on surgical exloration. [Figure 3].

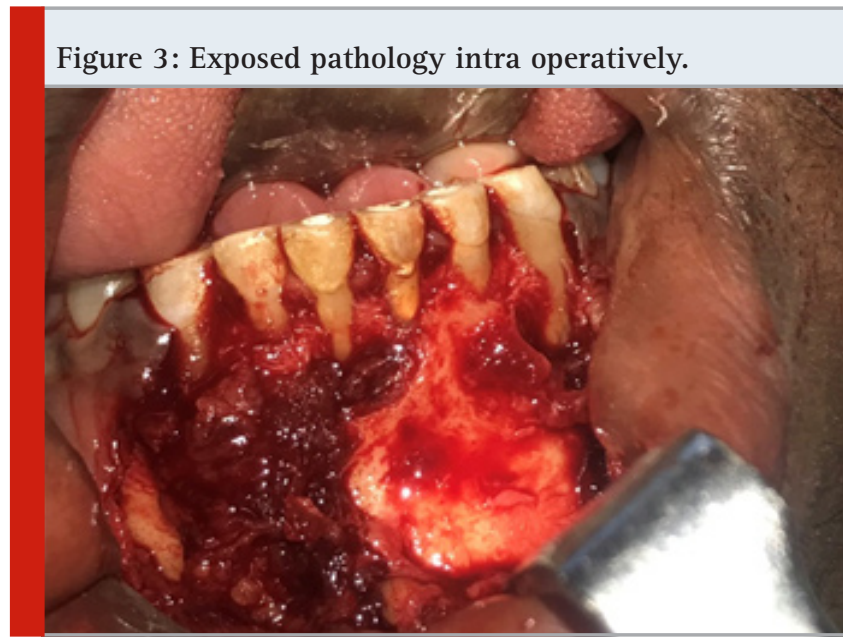

Figure 4: (a) Enucleation of the lesion and post- enucleation prophylactic saucerized bone. (b) Concentrated growth factors along with the osseous reconstruction xenograft(Bio Oss) placed for bone regeneration.

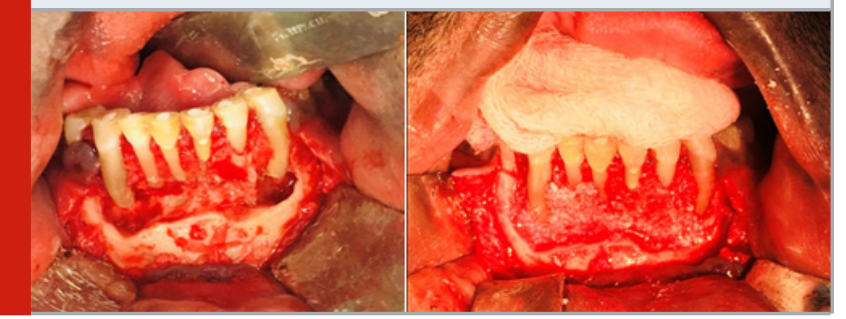

Figure 5: Enucleated pathological specimen

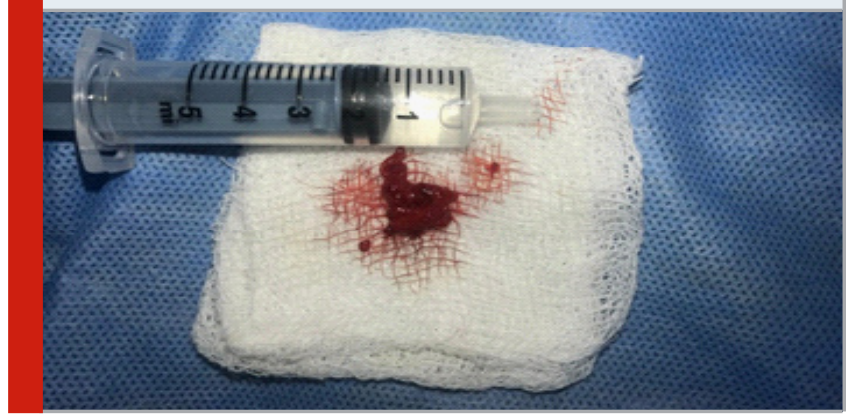

Concentrated growth factors were extracted from the patients blood along with the osseous reconstruction xenograft(Bio Oss) acting as both a membrane and a growth potentiating component to enhance the development of neovascularization and osseous reformation. [Figure 4]. The specimen on histopathological analysis showed odontogenic epithelial lining with non keratinized stratified squamous epithelium of variable sizes. The connective tissue wall was dense and fibrous composed of several foci of intense chronic inflammatory cells. It also showed proliferating odontogenic epithelial rest cells with squamous metaplastic changes along with vacuolization of cells. Moderate vascularization and evidence of hemorrhage was also evident. Areas of peripheral resorbing bone were seen with evidence of an area of overlying stratified squamous epithelium. [Figure 5]

Figure 6: Histopathological microscopic examination of the pathological specimen.

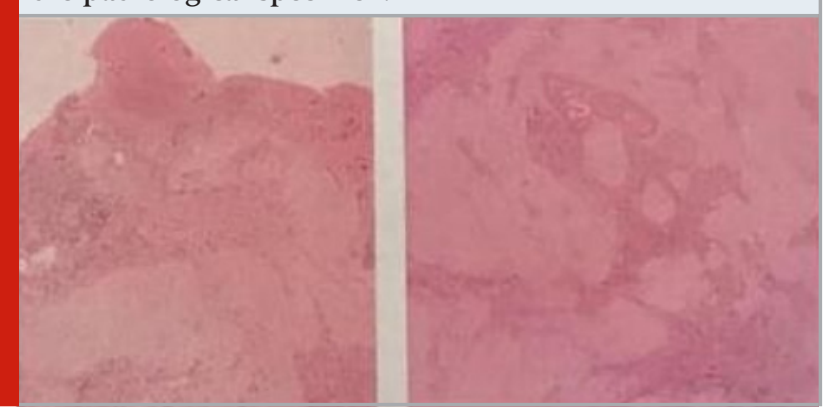

The histopathological report stated it as suggestive of inflammatory odontogenic cyst with squamous odontogenic tumor-like projections. [Figure 6]. The patient underwent regular follow-ups every week for the first month post operatively and 6 months post operatively, with no clinical symptoms nor complaint about any pressure or sensitivity disturbances in the affected area. [Figure 7 \& 8].

Figure 7: Postoperative orthopantomography image.

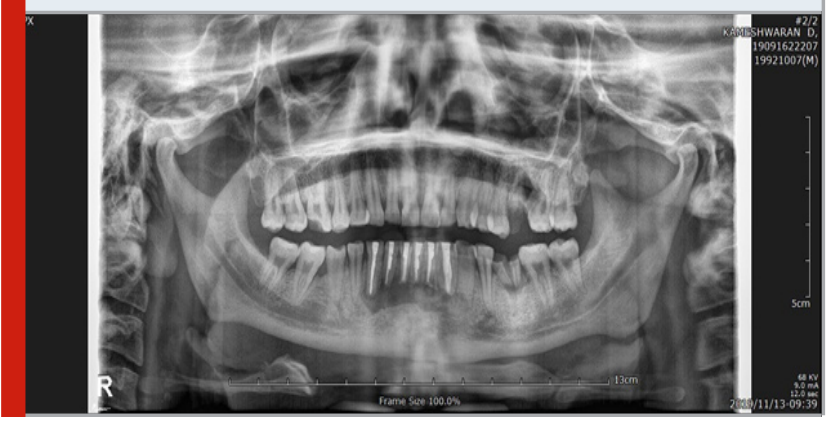

Figure 8: Image of One week follow up postoperatively.

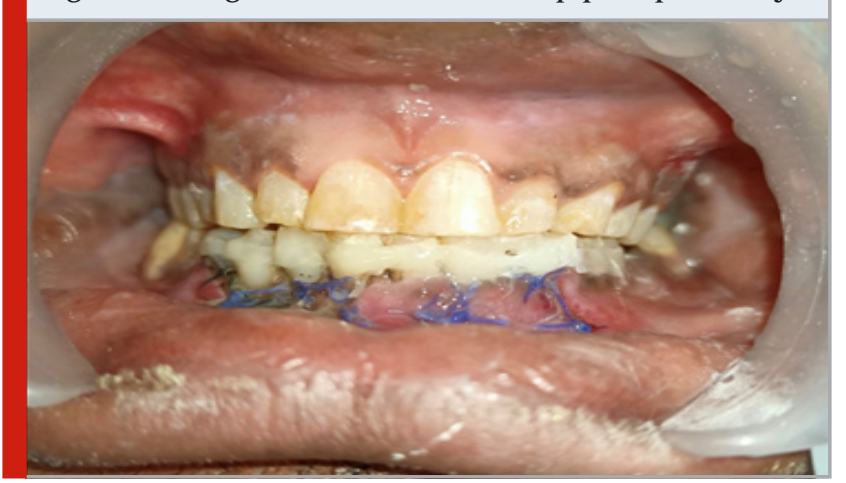




\section{DISCUSSION}

Squamous odontogenic tumors are rare, benign, locally infiltrative neoplasms that many authors have elicited about. Many authors have indiscriminately and extensively studied and described cases of squamous odontogenic tumor in the past. (Pullon et al., 1975; Doyle et al., 1977; Hopper, Sadeghi and Pricco, 1980; McNeill, Price and Stoker, 1980; van der Waal, de Rijcke and van der Kwast, 1980; Carr, Carlton and Marks, 1981; Goldblatt, Brannon and Ellis, 1982; Cataldo, Less and Giunta, 1983; Norris et al., 1984; Kristensen, Andersen and Jacobsen, 1985; Monteil and Terestri, 1985; Warnock et al., 1985; Mills et al., 1986; Leider, Jonker and Cook, 1989; Baden et al., 1993; Kusama et al., 1998; Perdigão et al., 2004; Ruhin et al., 2007; Siar et al., 2010; Malathi et al., 2012; Bansal and Joshi, 2013; Virapara, Rajput and Shah, 2018)

On comparing with cases of SOT diagnosed world wide, the age at the time of initial diagnosis ranged between 8 and 67 years, with a mean age of 36.3 years. Patients aged 20-29 show an increased rise in the visibility of SOT's. The gender ratio of female to male predilection from as reported in the literature ranges from 1:1.2 to $1: 1.4$. The mandible was involved in $57.1 \%$ of all cases and the maxilla in only $38.8 \%$ with remaining having variations in the site of occurrence.

According to the present literature, the incidence of SOT is low with just over 50 cases reported worldwide. The tumor usually grows slowly and demonstrates a lack of symptoms for a long standing period of time. The radiographic and clinical characteristic features of SOT are neither unique nor sufficient for the final diagnosis and because of which, chances are that SOT may be confused with a number of other pathologies(Perdigão et al., 2004). Therefore, distinctive clinical, radiological and histological aspects are necessary for avoiding a misdiagnosis that may result in serious negative implications for the patient (Ide et al., 1999). There has been an increased predominance in the third decade for SOT, however studies have proved it to appear in any age. The youngest patient reported in the literature was a 9-year-old boy with maxillary SOT that was treated with local surgical tumorectomy.(Ide et al., 1999; Ruhin et al., 2007)(10). The maxilla appears to be involved more often in the region of the incisors, whereas the premolar and molar areas appear to be more involved in the mandible.

SOT presents as a locally infiltrative neoplasm and has been known to infiltrate into adjacent tissues, with resorption of the alveolar bone and invasion of the overlying gingival and oral mucosa. (Robson, 2001) The etiology of SOT is yet to be interpreted for correct and rightful diagnosis with timely effect. However, immunohistochemical evaluation performed in studies described in literature revealed positive reactivity of varying intensity in the neoplastic epithelial cells for the Notch1, Notch2 and Notch3 transmembrane receptors and their ligands. These findings suggest that these receptors play a role in the cytodifferentiation of squamous odontogenic tumors.(Siar et al., 2010).

Although squamous odontogenic tumors are considered to be benign neoplasms, the local expansiveness and clinical behaviour of the tumor indicates the possibility of carcinomatous transformation. In 1999, Ide et al (Ide et al., 1999) reported a rare occurrence of intraosseous squamous cell carcinoma arising in association with squamous odontogenic tumors. The enucleated specimen of the tumor revealed a characteristic pattern of SOT. However, within 2 months, aggressive bone destruction exhibiting the typical findings of intraosseous squamous carcinoma was described. Recent studies have revealed that an odontogenic tumor, which is difficult to access, is prone to the development of recurrence. This may be due to the inability of the surgical treatment to fully remove all tumor cells due to lack of accessibility or due to its normal like morphology..(Ide et al., 1999).

Treatment of SOT consists of the surgical enucleation of the whole lesion, curettage of the affected area with extraction of the affected teeth, if present. More extensive lesions with infiltrating neighboring structures require more radical interventions such as en bloc resection. (Jones et al., 2011; Badni, Nagaraja and Kamath, 2012; Tarsitano, Agosti and Marchetti, 2012; Bansal and Joshi, 2013): (Baden et al., 1993) CGF, Concentrated Growth Factors are described as a miracle in regenerative dentistry. CGF is a new regeneration platelet aggregate which is used widely in oral surgeries. It contains various growth factors which enhances its action and promotes wound healing and growth potentials. CGF is currently used best with autologous bone particles to help induce bone regeneration and connective tissue attachment. CGF is a fibrin tissue adhesive with properties of haemostasis and tissue sealant properties making it effective on placement. It accelerates osteogenesis and promotes wound healing. CGF improves the stability of the wound that is required for the attachment of a new connective tissue to the root surface. It promotes epithelial, endothelial and epidermal regeneration and decreases scarring.

It has antimicrobial properties due to high concentration of leukocytes. It acts as an anti-antigenic agent on chronic non healing wounds.(Y, 2018) Its most important factor is the induction of bone regeneration when added to xenografts like Bio Oss which potentiates and plays a vital role in the regeneration of lost or cauterized bone in the course of enucleation of a pathology. Many factors have contraindicated with literature in this described case making it indeed paradoxical pathology. The most common site of occurrence as per literature in mandible was the posterior region,(Perdigão et al., 2004) whereas in this case, SOT was present in the mandibular anterior region extending for the right mandibular canine to the left mandibular canine region. However in sync with the literature, the tooth was non vital and radiographically exhibited a triangular radiolucency of the peri apical region of the involved teeth. 


\section{ACKNOWLEDGEMNTS}

The authors thank Dr Jones for his support in providing the images needed to complete this case report.

\section{REFERENCES}

Abdul Wahab, P. U. et al. (2017) 'Risk Factors for Postoperative Infection Following Single Piece Osteotomy’, Journal of maxillofacial and oral surgery, 16(3), pp. 328-332.

Abhinav, R. P. et al. (2019) 'The Patterns and Etiology of Maxillofacial Trauma in South India', Annals of maxillofacial surgery, 9(1), pp. 114-117.

Baden, E. et al. (1993) 'Squamous odontogenic tumor. Report of three cases including the first extraosseous case', Oral surgery, oral medicine, and oral pathology, 75(6), pp. 733-738.

Badni, M., Nagaraja, A. and Kamath, V. (2012) 'Squamous odontogenic tumor: A case report and review of literature', Journal of oral and maxillofacial pathology: JOMFP, 16(1), pp. 113-117.

Bansal, S. and Joshi, S. K. (2013) 'Squamous odontogenic tumor with unusual localization and appearance: a rare case report', Case reports in medicine, 2013, p. 407967.

Carr, R. F., Carlton, D. M., Jr and Marks, R. B. (1981)

'Squamous odontogenic tumor: report of case', Journal of oral surgery , 39(4), pp. 297-298.

Cataldo, E., Less, W. C. and Giunta, J. L. (1983) 'Squamous odontogenic tumor. A lesion of the periodontium', Journal of periodontology, 54(12), pp. 731-735.

Cillo, J. E., Ellis, E. and Kessler, H. P. (2005) 'Pericoronal squamous odontogenic tumor associated with an impacted mandibular third molar: A case report', Journal of Oral and Maxillofacial Surgery, pp. 413-416. doi: 10.1016/j.joms.2004.11.008.

Doyle, J. L. et al. (1977) 'Squamous odontogenic tumor: report of three cases', Journal of oral surgery , 35(12), pp. 994-996.

Eapen, B. V., Baig, M. F. and Avinash, S. (2017) 'An Assessment of the Incidence of Prolonged Postoperative Bleeding After Dental Extraction Among Patients on Uninterrupted Low Dose Aspirin Therapy and to Evaluate the Need to Stop Such Medication Prior to Dental Extractions', Journal of maxillofacial and oral surgery, 16(1), pp. 48-52.

Goldblatt, L. I., Brannon, R. B. and Ellis, G. L. (1982) 'Squamous odontogenic tumor', Oral surgery, oral medicine, and oral pathology, 54(2), pp. 187-196.

Haghighat, K., Kalmar, J. R. and Mariotti, A. J. (2002) 'Squamous odontogenic tumor: diagnosis and management', Journal of periodontology, 73(6), pp. 653-656.

Hopper, T. L., Sadeghi, E. M. and Pricco, D. F. (1980) 'Squamous odontogenic tumor', Oral surgery, oral medicine, and oral pathology, 50(5), pp. 404-410.

Ide, F. et al. (1999) 'Intraosseous squamous cell carcinoma arising in association with a squamous odontogenic tumour of the mandible', Oral oncology, 35(4), pp. 431-434.

Jain, M. and Nazar, N. (2018) 'Comparative Evaluation of the Efficacy of Intraligamentary and Supraperiosteal Injections in the Extraction of Maxillary Teeth: A Randomized Controlled Clinical Trial', The journal of contemporary dental practice, 19(9), pp. 1117-1121.

Jones, B. E. et al. (2011) 'Squamous odontogenic tumor', Head and neck pathology, 5(1), pp. 17-19.

J, P. C. et al. (2018) 'Prevalence and measurement of anterior loop of the mandibular canal using CBCT: A cross sectional study', Clinical implant dentistry and related research, 20(4), pp. 531-534.

Kim, K., Mintz, S. M. and Stevens, J. (2007) 'Squamous odontogenic tumor causing erosion of the lingual cortical plate in the mandible: a report of 2 cases', Journal of oral and maxillofacial surgery: official journal of the American Association of Oral and Maxillofacial Surgeons, 65(6), pp. 1227-1231.

Kristensen, S., Andersen, J. and Jacobsen, P. (1985) 'Squamous odontogenic tumour: review of the literature and a new case', The Journal of laryngology and otology, 99(9), pp. 919-924.

Kusama, K. et al. (1998) 'Squamous odontogenic tumor of the maxilla: report of a case', Journal of oral science, 40(3), pp. 119-122.

Leider, A. S., Jonker, L. A. and Cook, H. E. (1989) 'Multicentric familial squamous odontogenic tumor', Oral surgery, oral medicine, and oral pathology, 68(2), pp. 175-181.

Malathi, N. et al. (2012) 'Peripheral squamous odontogenic tumor', Indian journal of dental research: official publication of Indian Society for Dental Research, 23(2), pp. 286-288.

Marimuthu, M. et al. (2018) 'Canonical Wnt pathway gene expression and their clinical correlation in oral squamous cell carcinoma', Indian journal of dental research: official publication of Indian Society for Dental Research, 29(3), pp. 291-297.

McNeill, J., Price, H. M. and Stoker, N. G. (1980) 'Squamous odontogenic tumor: report of case with long-term history', Journal of oral surgery , 38(6), pp. 466-471.

Mills, W. P. et al. (1986) 'Squamous odontogenic tumor', Oral surgery, oral medicine, and oral pathology, 61(6), pp. 557-563.

Monteil, R. A. and Terestri, P. (1985) 'Squamous odontogenic tumor related to an unerupted lower canine', Journal of oral and maxillofacial surgery: official journal of the American Association of Oral and Maxillofacial Surgeons, 43(11), pp. 888-895.

Norris, L. H. et al. (1984) 'Bilateral maxillary squamous odontogenic tumors and the malignant transformation of a mandibular radiolucent lesion', Journal of oral and maxillofacial surgery: official journal of the American Association of Oral and Maxillofacial Surgeons, 42(12), 
pp. 827-834.

PARADOXICAL | meaning in the Cambridge English Dictionary (no date). Available at: https://dictionary. cambridge.org/dictionary/english/paradoxical (Accessed: 3 July 2020).

Patil, S. B. et al. (2017) 'Comparison of Extended Nasolabial Flap Versus Buccal Fat Pad Graft in the Surgical Management of Oral Submucous Fibrosis: A Prospective Pilot Study', Journal of maxillofacial and oral surgery, 16(3), pp. 312-321.

Perdigão, P. F. et al. (2004) 'Ameloblastin gene (AMBN) mutations associated with epithelial odontogenic tumors', Oral oncology, 40(8), pp. 841-846.

Philipsen, H. P. and Reichart, P. A. (1996) 'Squamous odontogenic tumor (SOT): a benign neoplasm of the periodontium. A review of 36 reported cases', Journal of clinical periodontology, 23(10), pp. 922-926.

Philipsen, H. P. and Reichart, P. A. (2006) 'Classification of odontogenic tumours. A historical review', Journal of Oral Pathology and Medicine, pp. 525-529. doi: 10.1111/j.1600-0714.2006.00470.x.

Pullon, P. A. et al. (1975) 'Squamous odontogenic tumor. Report of six cases of a previously undescribed lesion', Oral surgery, oral medicine, and oral pathology, 40(5), pp. 616-630.

Ramadorai, A., Ravi, P. and Narayanan, V. (2019) 'Rhinocerebral Mucormycosis: A Prospective Analysis of an Effective Treatment Protocol', Annals of maxillofacial surgery, 9(1), pp. 192-196.

Reichart, P. A. and Philipsen, H. P. (1990) 'Squamous odontogenic tumor', Journal of Oral Pathology and Medicine, pp. 226-228. doi: 10.1111/j.1600-0714.1990. tb00830.x.

Robson, D. K. (2001) 'Pathology \& Genetics. Tumours of the Nervous System. World Health Organisation Classification of Tumours. P. Kleihues and k. Cavenee (eds). IARC Press, Lyon, 2000. No. of pages: 314. ISBN: 928322409 4', The Journal of Pathology, pp. 276-276. doi: 3.0.co;2-q">10.1002/10969896(200102)193:2<276::aid-path765>3.0.co;2-q.

Ruhin, B. et al. (2007) 'Aggressive maxillary squamous odontogenic tumour in a child: histological dilemma and adaptative surgical behaviour', International Journal of Oral and Maxillofacial Surgery, pp. 864-866. doi: 10.1016/j.ijom.2007.03.002.
Saxby, M. S., Rippin, J. W. and Sheron, J. E. (1993) 'Case report: squamous odontogenic tumor of the gingiva', Journal of periodontology, 64(12), pp. 1250-1252.

Senthil Kumar, M. S. et al. (2019) 'Inflammatory pseudotumour of the maxillary sinus: clinicopathological report', Oral Surgery, 12(3), pp. 255-259.

Siar, C. H. et al. (2010) 'Squamous odontogenic tumor of the mandible: a case report demonstrating immunoexpression of Notch1, 3, 4, Jagged 1 and Delta1', European journal of medical research, 15(4), pp. 180-184.

Sweta, V. R., Abhinav, R. P. and Ramesh, A. (2019) 'Role of Virtual Reality in Pain Perception of Patients Following the Administration of Local Anesthesia', Annals of maxillofacial surgery, 9(1), pp. 110-113.

Tarsitano, A., Agosti, R. and Marchetti, C. (2012) 'The diagnostic and surgical management of a multifocal calcifiyng epithelial odontogenic tumor in the mandible and maxilla associated with a squamous odontogenic tumor: first reported case in the literature', Oral surgery, oral medicine, oral pathology and oral radiology, 113(4), pp. e6-11.

Virapara, H., Rajput, D. and Shah, D. (2018) 'Case Report a Rare Case Report of Yolk Sac Tumor', Indian journal of applied basic medical sciences. doi: 10.26860/ ijabms.2018.30.20a.24.

van der Waal, I., de Rijcke, T. B. and van der Kwast, W. A. (1980) 'Possible squamous odontogenic tumor: report of case', Journal of oral surgery , 38(6), pp. 460-462.

Wahab, P. U. A. et al. (2018) 'Scalpel Versus Diathermy in Wound Healing After Mucosal Incisions: A SplitMouth Study', Journal of oral and maxillofacial surgery: official journal of the American Association of Oral and Maxillofacial Surgeons, 76(6), pp. 1160-1164.

Warnock, G. R. et al. (1985) 'Triangular-shaped radiolucent area between roots of the mandibular right canine and first premolar', Journal of the American Dental Association , 110(6), pp. 945-946.

World Health Organization and International Agency for Research on Cancer (2005) Pathology and Genetics of Head and Neck Tumours. IARC.

Y, P. K. (2018) 'Role of CGF (Concentrated Growth Factor) in periodontal regeneration', Journal of Dental Health, Oral Disorders \& Therapy. doi: 10.15406/ jdhodt.2018.09.00407. 